\title{
A função emotiva em perspectiva intercultural
}

Olga Donata Guerizoli Kempinska

Resumo: Este artigo propõe uma discussão sobre a relação entre a função emotiva e o multilinguismo. Ao problematizar as duas principais abordagens teóricas dessa relação, a visão da língua materna como o único verdadeiro veículo das emoções, por um lado, e, por outro, a visão da segunda língua como possibilidade de recombinação criativa dos scripts emocionais, o artigo insiste no interculturalismo como uma perspectiva válida para a pesquisa das emoções na linguagem humana. Confrontando as reflexões teóricas de Wierzbicka e de Pavlenko, ambas influenciadas pela emigração, com a situação cada vez mais desterritorializada da linguagem poética, o texto visa a enfatizar a ambivalência da articulação discursiva das emoções.

Palavras-chave: função emotiva; multilinguismo; interculturalismo.

Abstract: An intercultural perspective of the emotive function - This paper discusses the relationship between the emotive function and multilingualism. By discussing the two main theoretical approaches of this relationship - on the one hand, the vision of the mother tongue as the only true medium of emotions, and on the other, the vision of the second language as a possibility for the creative recombination of emotional scripts -, this article insists on interculturalism as a valid perspective for research about emotions in human language. Comparing the theoretical reflections of Anna Wierzbicka and Aneta Pavlenko, both of whom were influenced by emigration, with the increasingly deterritorialized status of poetic language, this text aims to emphasize the ambivalence of the discursive articulation of emotions.

Keywords: emotive function; multilingualism; interculturalism.

"A função emotiva, evidenciada pelas interjeições, colore, em certa medida, todas as nossas manifestações verbais, ao nível fônico, gramatical e lexical" (JAKOBSON, 1995, p. 124). Apesar de sua abrangência, responsável pela pluralidade de suas manifestações discursivas, a função emotiva resulta, no entanto, bastante difícil de ser estudada de maneira sistemática. Particularmente desafiante revela-se a reflexão sobre a presença, sobretudo na escrita, de elementos paralinguísticos, tais como a mímica e os gestos, 
e prosódicos, tais como a velocidade e o volume da voz. São, no entanto, justamente esses elementos, que, ao remeterem a manifestações corporais, apontam para uma componente importante do próprio conceito de emoção, pelo menos tal como expresso pela palavra "emotion" em inglês e pela palavra "emoção" em português. Wierzbicka sublinha, nesse sentido, a abrangência da noção de "emotion" em inglês, cujo sentido remete a uma construção plural, composta não apenas do pensamento e do sentimento, mas também da reação do corpo (Cf. WIERZBICKA, 1999, p. 2). É, aliás, a presença dessa última componente, a corporal, que faz com que "emotion", da qual a palavra "emoção" em português é um equivalente bastante fiel, seja às vezes dificilmente traduzível em outras línguas.

O exemplo que ilustra a função emotiva no conhecido texto Linguística e poética de Jakobson é aquele de um antigo ator do Teatro Stanislavski de Moscou, que, participando da pesquisa, variou dezenas de vezes a nuance expressiva da expressão "esta noite". Seu desempenho levou a uma interpretação muito bem sucedida: "Em sua maior parte, as mensagens foram correta e circunstanciadamente decodificadas por ouvintes moscovitas" (JAKOBSON, 1995, p. 125). Mas o texto de Jakobson, limitando-se à constatação da presença da função emotiva, "centrada no remetente" e que "visa a uma expressão direta da atitude de quem fala em relação àquilo de que está falando" (ibid., pp. 124-125), não desenvolve nenhum questionamento acerca do que exatamente seria tal atitude, nem quais seriam os elementos relevantes de sua recepção.

Em oposição ao exemplo jakobsoniano, cuja simplicidade e cujas limitações resultam, por um lado, do fato de que os interlocutores envolvidos naquela experiência compartilhavam do mesmo contexto linguístico e cultural, e, por outro, da falta de simetria entre os participantes - o ator era um profissional -, os estudos recentes privilegiam como campo de pesquisa das emoções no discurso situações menos artificiais e menos óbvias. Nesse sentido, acompanhadas pela intensificação da reflexão em torno à dimensão cognitiva das emoções, as pesquisas contemporâneas valorizam, como seu âmbito, o multilinguismo, enxergando nele um domínio particularmente interessante para estudo das relações entre as articulações discursivas e as manifestações dos afetos.

De fato, dentre as situações de risco, nas quais tanto a coerência da emoção, quanto sua expressão linguística e sua interpretação se encontram ameaçadas, permitindo, ao mesmo tempo, uma observação mais completa do próprio funcionamento das emoções, um lugar proeminente passa a ser ocupado pelos discursos produzidos no contexto intercultural. "Um inglês não poderia usar em inglês a palavra 'sentiment' nos sentidos que tem 'le sentiment' em francês, expressão parecida na pronúncia, mas funcionalmente diferente" (WHORF, 2012, p. 316). A partir da perspectiva do multilinguismo, a vulnerabilidade e a instabilidade transformam-se em importantes instrumentos de investigação. E mesmo que o relativismo linguístico em sua forma radical, de acordo com a qual o pensamento seria completamente determinado pelas estruturas de uma dada língua, seja dificilmente sustentável, as diferenças linguísticas que dizem respeito à expressão e à interpretação das emoções não deixam de ser evidentes. 
Tomando-se como ponto de partida a relevância do multilinguismo para o estudo do funcionamento das emoções no discurso, chamam atenção particular as pesquisas de Wierzbicka e de Pavlenko. Sem dúvida inspirados pelas experiências pessoais da emigração, da Polônia para a Austrália, no caso de Wierzbicka, e da Ucrânia para os Estados Unidos, no caso de Pavlenko, os trabalhos das duas linguistas estão em sintonia com uma repercussão considerável do multilinguismo sobre a literatura contemporânea. O bilinguismo estratégico de Beckett e a língua desterritorializada de Kafka, por um lado, e o trabalho efetuado sob o impacto da emigração e do contato com uma outra língua por parte de poetas tais como Marina Tsvetáieva, Halina Poświatowska, Czesław Miłosz e Julia Hartwig, por outro, permitem, de fato, abordar o problema da relação entre o discurso e as emoções através de uma pergunta que logo aponta para uma situação de carência, não desprovida de características viscerais: $\mathrm{O}$ que acontece com a função emotiva em uma outra língua?

\section{O apelo lácteo da língua materna}

O uso de uma nova língua, aprendida de maneira consciente na adolescência ou na idade adulta, é por vezes visto como altamente corrosivo tanto para a expressão quanto para a própria experiência das emoções. E foi justamente dessa maneira que Beckett, o primeiro a transformar o multilinguismo em um problema poético, interpretou o uso do francês. Em uma carta de 1937, endereçada a um amigo alemão, Beckett explicitou o papel estratégico da nova língua na almejada atividade corrosiva contra a língua materna: "Consolo-me apenas de vez em quando, como agora, de poder, involuntariamente, causar estragos a uma língua estrangeira, como gostaria de causar, premeditada e deliberadamente, à minha - e como ainda farei". (BECKETT in. CLÉMENT, 1994, p. 239).

Em que consiste, aos olhos de Beckett, a atividade de causar estragos à sua língua? Ou, antes, qual é exatamente o elemento da língua que o escritor deseja estragar? Em Dias felizes, de 1961, um daqueles textos que serão escritos, de volta, primeiro na língua materna, em inglês, para serem depois traduzidos para o francês, é interessante reler o fragmento, no qual a personagem Winnie evoca suas primeiras experiências amorosas. A passagem foi traduzida no Brasil literalmente da edição em inglês: "Meu primeiro baile! (Pausa longa.) Meu segundo baile! (Pausa longa. Fecha os olhos.) Meu primeiro beijo! (Pausa. WILLIE vira a página. WINNIE abre os olhos.) Um certo Johnson, ou era Johnston, não, talvez Johnstone fosse o nome." (BECKETT, 2010, p. 34). Reescrito em francês, o fragmento conservará a mesma estrutura da repetição do evento e da incerteza chistosa quanto ao nome próprio, mas acrescentará ainda a profissão, incerta, do namorado, cujo nome, em correspondência com o nome próprio banal em inglês, também será adaptado ao contexto: "Un kinési ou mécanothérapeute Demoulin...ou Dumoulin...voire encore Desmoulins c'est encore possible" (BECKETT, 1963, p. 22). 
$\mathrm{Na}$ leitura dessas passagens, o leitor experimenta, de fato, que algo se corrompe. As lembranças de Winnie, em vez de se deterem no núcleo das emoções amorosas inaugurais, aquelas do primeiro baile e do primeiro beijo, que correspondem às narrativas típicas da história do primeiro amor, deslizam na direção da enumeração e do trocadilho com nomes próprios - Johnson, Demoulin e suas respectivas variantes -, ainda multiplicado mais pelo recurso às duas línguas. E se o riso é uma das reações possíveis na leitura desse trecho, é porque, ao introduzir o elemento da repetitividade do acontecimento e da proliferação do nome do namorado, o texto se opõe à expectativa da expressão verbal das emoções que acompanham a experiência supostamente excepcional, única e, com isso, inconfundível e inesquecível. Em uma palavra, o texto beckettiano anuncia uma atmosfera emocional apenas para logo estragá-la.

Embora não seja colocada em uma relação direta como o bilinguismo do autor pela pesquisadora americana, essa forma de estrago é interpretada por Nussbaum como a estratégia tipicamente beckettiana do desaprendizado das emoções, que não sendo naturais, mas socialmente adquiridas, possuem um importante valor epistemológico e modelam a existência humana. "Se as emoções não são sensações naturais mas, antes, construções, se elas se baseiam nas crenças, podem, então, ser modificadas pela modificação da crença" (NUSSBAUM, 1990, p. 292).

É importante perceber que, na visão dos textos de Beckett enquanto inscritos em um amplo projeto de desescrever as histórias, - aquelas, por exemplo, sobre o amor envolvido com as ideias de finitude e de pecado, que levam à elaboração da estrutura da busca pela culpa - e de desfazer a coerência das emoções relacionadas com essas histórias, o bilinguismo, justamente por causa do seu suposto potencial de "causar estragos", desempenha o papel central, permitindo uma quebra radical da unidade emocional do discurso.

Se Beckett tentou aproveitar a experiência do francês para corromper a unidade emocional de seus textos é porque, de fato, o uso da língua não materna como meio de expressão tende a prejudicar a coerência afetiva do discurso, levando com frequência a falhas na transmissão correta tanto do tipo quanto da intensidade das emoções:

Tentar contar uma história de uma forma adequada em uma nova língua é uma tarefa difícil. Torna-se ainda mais desafiadora quando os contadores empreendem a descrição de suas emoções e a estimulação de uma reação emocional determinada nos interlocutores. Para consegui-lo, os contadores de histórias precisam estar familiarizados com as convenções das estruturas narrativas e com os dispositivos afetivos e ser capazes de adotar de uma forma criativa esses dispositivos ao público. (PAVLENKO, 2005, p. 122)

Ao relatar diversas experiências da narração de histórias em uma língua não materna, feitas por pessoas de diferentes contextos sociolinguísticos, Pavlenko, em seu livro Emotions and Multilingualism, de 2005, nota não apenas a presença de dificuldades 
de vocabulário - o fato de que, no nível lexical, faltam termos equivalentes para nomear uma emoção -, mas também uma carência considerável no que tange ao recurso, aos detalhes e à linguagem figurativa, que, enraizados na realidade sócio-histórica, são muito importantes como estímulos para a elaboração de imagens mentais por parte dos fruidores, determinantes, por sua vez, para as reações afetivas.

Marina Tsvetáieva chamou essa relação íntima entre a língua materna e as emoções de "apelo lácteo". Em um poema amargo, escrito em 1934, em Paris, uma das várias cidades para as quais a poeta escapara da fome que assomava a Rússia revolucionária, Tsvetáieva, que não havia renunciado à língua russa em favor de nenhuma das línguas bem por ela conhecidas, o francês e o alemão, evocava o "apelo lácteo", que associava a língua materna com as emoções pré-verbais da primeira infância:

O apelo lácteo da língua nativa

Não me cativa mais

Para sentir-me incompreendida

A fala - tanto faz!

(...)

Estranhas as casas, vazios os templos,

Tudo igual - indiferente.

E só a árvore, que surge na beira

De uma estrada - é uma sorveira...

(TSVETÁlEVA et al., 1995, p. 136-138)

Apesar da amargura, que por um momento parece levar à perda da eficácia do apelo lácteo da língua materna, seu poder é reafirmado no final do poema, no surgimento da "sorveira", palavra-árvore nativa. À persistência do apelo lácteo relaciona-se, de fato, à dificuldade de se transplantar a função emotiva em uma nova língua, que é, sem dúvida, ao lado da relação com o público, um dos principais motivos da recusa obstinada de tantos escritores emigrantes, entre os quais, por exemplo, Czesław Miłosz, a renunciar à língua materna enquanto língua da escrita. Continuando, nesse sentido, uma tradição romântica do escritor no exílio, da qual Joseph Conrad havia sido o primeiro a escapar, preparando o caminho de Vladimir Nabokov, apesar de terem passado décadas fora do país natal, muitos escritores empenhavam-se em preservar a língua materna. Tratava-se frequentemente de um verdadeiro cultivo, como se a língua materna na emigração, transformada em uma planta frágil, uma bétula mal-aclimatada ao solo estranho da Califórnia, necessitasse de cuidados especiais. Assim, por exemplo, em um poema de Miłosz, composto em Berkeley em 1968, a nutrição da língua materna se dá através de lembranças e sonhos, que restauram as conotações afetivas das palavras relacionadas ao contexto da infância do poeta na Lituânia: 
Minha língua fiel, eu fui teu servidor.

Toda noite te oferecia tigelas com cores, para que tivesses a bétula, o grilo, o dom-fafe conservados em tua memória. (...)

(MIŁOSZ, 2011, p. 594)

Tanto o uso corrosivo da nova língua por Beckett, quanto à sensação de que a língua materna pode ser enfraquecida ou ameaçada pela experiência da emigração apontam para a convicção, segundo a qual o uso da nova língua, marcado pelo estranhamento e pela infantilização, tem em si algo de uma patologia. De fato, ao despojar o discurso de seu primeiro enraizamento afetivo, o multilinguismo parece como inseparável da anomia e da ansiedade, que, por sua vez, põem o bem-estar do sujeito em risco. O limite de tal patologia, cujo potencial corrosivo foi sabiamente controlado e aproveitado na obra de Beckett, consistiria na dispersão radical e no desaparecimento da linguagem e do sujeito. Uma encenação da realização dessa ameaça surge, por exemplo, no texto Quando dizemos o quê, um dos poemas americanos de Julia Hartwig, escritos no início dos anos 1970, durante a primeira estada da poeta polonesa nos Estados Unidos:

Espalhem minhas cinzas no oceano

Será que ela realmente achava que podemos fazê-lo

Ó gotas secas de lágrimas

não estamos mais na época em que se morre de saudade

Em poucas horas podemos estar de volta batendo na porta dos amigos

Mas não a todos é dado esse privilégio

Às vezes celebra-se com chucrute e cogumelos os Ancestrais

Mas há quem não queira mais festejar

e morre de uma cirrose geral

Aquele que encontrei hoje na Terceira Avenida

estava no meio da calçada uivando com uma voz de cão

Dizemos às vezes ao voltar de uma viagem

como são maravilhosas as capitais onde se pode se perder na multidão mas dizemos isso ao voltar.

(HARTWIG, 2002, p. 30)

O poema, tão rico em associações literárias do romantismo polonês, desde seu título anuncia o problema da relação entre o discurso e o espaço. A dedicatória "Para Hania in memoriam" e a imagem das cinzas espalhadas no oceano tornam essa relação mais dramática, apontando para a unanimidade paradoxal que se instaura entre todo lugar e lugar nenhum. "No meio da calçada uivando com uma voz de cão" é 
a imagem assustadora dos efeitos corrosivos da perda da língua materna, da qual resulta a perda da língua em geral. A ubiquidade metropolitana leva aqui, com efeito, à perda da linguagem humana enquanto forma de comunicação. Falta radical transformada em excesso radical, a explosão da função emotiva parece ter eliminado todas as outras funções, transformando a linguagem humana em linguagem animal.

\section{Entre línguas}

Pensar a relação entre o multilinguismo e as emoções é, sem dúvida, inseparável de uma reflexão sobre as relações complexas entre a língua, a cognição e a memória. Nessa situação, a língua materna, enquanto depósito dos primeiros afetos, tende a aparecer como o espaço privilegiado, se não único, da função emotiva. É possível permear de emoções uma outra língua?

"Se as pessoas não acreditassem na existência de 'outras línguas', então com exceção dos bilíngues de nascimento ou circunstâncias - seríamos todos monolíngues" (WIERZBICKA, 1997, p. 19). Por que haveria necessidade de uma segunda, nova, outra língua, que vem se justa ou se sobrepor à língua materna? Segundo Wierzbicka, a posição multilíngue revela-se privilegiada para a apreensão dos scripts emocionais. Os scripts remetem a cenários cognitivos, lexicalmente codificados, "que envolvem tanto pensamentos quanto sentimentos e que servem como ponto de referência para a identificação daquilo que os usuários dessa língua percebem como diversos tipos de emoções" (ibid., p. 15). Dessa forma, os scripts acabam sugerindo às pessoas, que compartilham uma realidade sociolinguística, como sentir, como expressar os sentimentos e como interpretar os sentimentos dos outros.

Discutindo com a perspectiva da carência emocional multilíngue, motivada pela ideia do enraizamento da vida emocional na língua materna, Pavlenko sugere que o multilinguismo tem como seu efeito não apenas uma melhor apreensão dos scripts emocionais, mas também a possibilidade de sua combinação criativa em novas construções. Ao fazer do multilinguismo não apenas o objeto, mas também o instrumento do estudo das emoções, e ao insistir no caráter dinâmico das relações entre as estruturas afetivas e suas expressões linguísticas, Pavlenko afasta-se das visões nativistas e simplistas, tanto daquelas que fazem da primeira língua uma "fala do coração", e, com isso, desproveem as outras línguas de potencial afetivo, quanto daquelas que enxergam na pluralidade linguística um composto de várias personalidades, e, com isso, de várias vidas. A pesquisadora ressalta, com isso, a especificidade da competência multilíngue: "um bilíngue não é a soma de dois monolíngues, completos ou incompletos, em um corpo, mas, antes, um locutor/receptor específico, com um sistema linguístico especial e, no entanto, completo" (PAVLENKO, 2005, p. 12). 
Um poema de Halina Poświatowska permite observar efeitos de uma elaboração criativa dos scripts emocionais, suscitada pela alteridade linguística. Fruto de uma longa estada da poeta polonesa nos Estados Unidos, cujo motivo inicial era uma operação devido a uma grave doença do coração, o texto proveniente do volume póstumo Uma lembrança a mais, de 1968, encena de forma instigante e não desprovida de ironia, a relação entre a língua e as emoções:

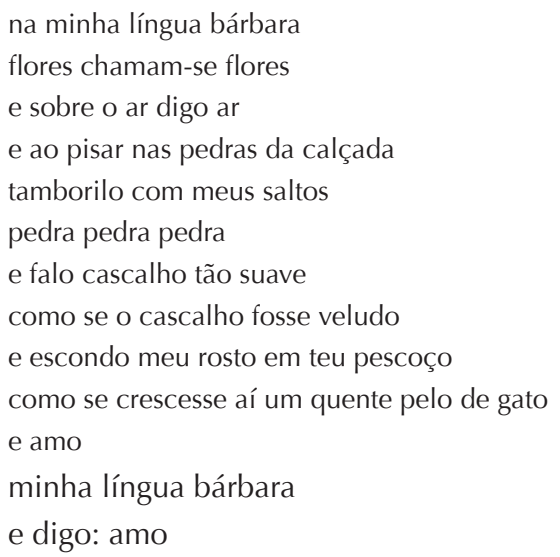

O poema encena um afeto com relação a e, ao mesmo tempo, na língua, tornando-se, dessa maneira, uma afirmação forte da proximidade entre a emoção e a língua materna. Mas essa mesma língua, amada e instrumento do amor, é qualificada desde o primeiro verso de "bárbara". Esse adjetivo, derivado pelos gregos de uma onomatopeia que apontava para o gaguejo e, com isso, para a falta de inteligibilidade, introduz um elemento de heterogeneidade na relação, aparentemente contínua e homogênea, entre o sujeito e a língua materna. Associado à ideia da fala incompreensível, longe de ser valorizante ou neutro, o qualificativo "bárbaro" remete, de fato, a um conjunto de traços linguísticos, antropológicos e políticos que apontam para a inferioridade e para exclusão: "Dizia-se que eram covardes, grosseiros, glutões, cruéis etc." (KOSELLECK, 2006, p. 198).

"Minha língua bárbara" é a expressão que circunscreve o poema em uma estrutura quase anelar, aproximando, paradoxalmente, o pronome possessivo em primeira pessoa e o epíteto que designa a alteridade. Próxima e distante, própria e alheia, apreciada e depreciada, a língua materna estabelece com as emoções uma relação ambígua. Ao chamá-la e ao experimentá-la como "bárbara" e ao hibridizar, com isso, a língua materna com a fala plural, inferior e incompreensível, Poświatowska, sem recorrer a formas de outro idioma, introduz, no entanto, na língua materna uma "poderosa e herética heteroglossia" (HARAWAY, 2009, p. 99). O contato com a língua estrangeira permite à poeta não apenas uma percepção mais aguda dos scripts emocionais, mas leva também 
à introdução da alteridade na língua própria. E a melhor transposição dessa poderosa e herética heteroglossia, vislumbrada por Haraway contra a poética e a estética da origem e do monolinguismo, seria uma tradução não apenas estrangeirizante, mas barbarizante:

na minha língua bárbara

flores chamam-se kwiaty

e sobre o ar digo powietrze (...)

(POŚWIATOWSKA, 1997, p. 118)

O próprio Miłosz, apesar de ter se empenhado tanto para resguardar a coerência e intensidade da dimensão afetiva das palavras da língua materna, protegendo-a contra os efeitos barbarizantes da emigração, acabou, parece, não completamente imune às repercussões da heteroglossia. Algumas de suas observações a respeito da língua polonesa parecem, de fato, impregnadas pela alteridade: "Heracidade da língua polonesa. Em oposição à autonomia, próxima das raízes folclóricas, da robustez do russo. Mas as heras e as trepadeiras não precisam ser consideradas inferiores." (MlŁOSZ, 2011, p. 833), notará o poeta, meditando, em 1984, sobre as vicissitudes da língua materna. Não é o recurso à figura do bárbaro, mas a evocação de uma planta trepadeira, a que coincide nessa imagem com a sonoridade cacofônica, irrecuperável na tradução, da palavra polonesa original "blusźćzowatosc".

Uma mesma ambivalência surge afinal também no poema de Miłosz Cardo, urtiga, de 1991, dois anos antes do retorno definitivo do poeta à Polônia. Mas os nomes específicos das plantas associadas à infância não se limitam aqui à evocação de um "apelo lácteo", pois são também imagens de ervas daninhas, plantas bárbaras, que invadirão no futuro um mundo pós-linguístico:

Cardo, urtiga, bardana, beladona

Têm futuro. A eles pertencem o terreno baldio

E os trilhos enferrujados, o céu, o silêncio.

Quem serei eu para as pessoas daqui a várias gerações,

Quando após o barulho das línguas vencerá o silêncio? (...)

(MIŁOSZ, 2011, p. 996)

Pensar a língua materna, as outras línguas e a função emotiva que as colore, revela-se, além de ambíguo, tal as plantas bárbaras da infância, também inseparável da história da literatura e da história da família. Particularmente evocativo é aqui a epígrafo: uma citação de Oscar Milosz, tio-avô lituano do poeta polonês, emigrante, simbolista, e que escrevia em uma segunda língua, o francês: “(...) le chardon et la haute Ortie et l'ennemie d'enfance belladonne". 
Se uma reformulação dos scripts da língua materna no contato com outra língua resulta não apenas possível, mas inevitável, é porque a relação da língua com as emoções talvez seja mesmo mais dinâmica do que aquela proposta pela aquisição determinante da língua na infância. De fato, quando considerada do ponto de vista da expressão linguística das emoções, a posição multilíngue não deixa de aparecer como ambivalente. Se, por um lado, a língua materna tende a ser vista como aquela que conserva a relação do sujeito com a experiência pré-verbal infantil, parecendo, assim, mais "natural" para a expressão visceral das emoções, por outro lado, muitas pessoas optam justamente pela impressão do controle das emoções possibilitado pela língua aprendida. Pavlenko relata, nesse sentido, que diversos psicanalistas haviam notado a preferência dada pelos analisandos multilíngues a uma análise na segunda língua (Cf. PAVLENKO, 2005, pp. 28-31).

Mas um controle seria realmente eficaz? Outra língua, afastada da experiência infantil, seria impermeável às emoções? As experiências vividas na segunda língua não a afetariam? Sem que eu possa responder definitivamente a essas perguntas, parece-me interessante trazer aqui um comentário acerca do uso das palavras obscenas, frequentemente experimentadas como mais emocionalmente impregnadas na língua materna, na qual, de fato, suscitam mais vergonha do em uma outra língua. No entanto, como nota com razão Adorno, essas mesmas palavras-tabus são também as mais facilmente reconhecíveis e assimiláveis em outra língua:

Sade no original dispensa dicionário. Mesmo as expressões mais remotas para indecências, cujo conhecimento não é transmitido por nenhuma escola, nenhum lar paterno e nenhuma experiência literária, são aprendidas, sonambúlicas, tal como na infância as mais remotas expressões e observações da vida sexual se combinam no conhecimento correto. É como se as paixões aprisionadas e chamadas pelo nome por essas palavras explodissem junto, com o dique da própria repressão, o das palavras cegas e golpeassem violentamente, irresistivelmente, a célula mais íntima do sentido, à qual se assemelham. (ADORNO, 2008, p. 44)

As palavras obscenas, investidas de uma carga emocional particularmente forte são, ao mesmo tempo, aquelas que suscitam reações mais fortes na língua materna e aquelas que são mais facilmente reconhecidas e emocionalmente remotivadas na outra língua. A velocidade da remotivação emocional das palavras obscenas em outra língua, coloca a relação entre a língua e as emoções sob o signo de um dinamismo um tanto selvagem. Os bárbaros, as plantas trepadeiras e as ervas daninhas parecem compartilhar um mesmo desrespeito pelas fronteiras.

Para completar essa conclusão provisória da reflexão sobre a língua materna, a outra língua e as emoções, cito ainda um pequeno texto poético de Kafka, no qual retorna o problema da ambivalência de todo enraizamento, inclusive o das emoções no discurso: "Pois somos como troncos de árvores na neve. Aparentemente eles jazem soltos 
na superfície e com um pequeno empurrão deveria ser possível afastá-los do caminho. Não, não é possível, pois estão firmemente ligados ao solo. Mas veja, até isso é só aparente" (KAFKA, 1999, p. 36). As árvores kafkianas, para além da diferença entre nomes genéricos, que remetem à universalidade desafetada dos conceitos, e os nomes específicos - como o da sorveira e da bétula -, que enraizariam a língua na singularidade da experiência, configuram-se, sobretudo, como uma imagem dinâmica. Soltas e presas.

Olga Donata Guerizoli Kempinska é doutora em História Social da Cultura pela PUC-Rio; seu mestrado em Filologia Românica foi realizado na Uniwersytet Jagiellonski de Cracóvia. Hoje é professora de Teoria da Literatura do Departamento de Ciências da Linguagem da Universidade Federal Fluminense. Publicou em 2011 o livro Mallarmé e Cézanne: obras em crise pela Editora Nau.

olgagkem@gmail.com

\section{Referências}

ADORNO, Theodor W. Mínima moralia. Rio de Janeiro: Beco do Azogue, 2008.

BECKETT, Samuel. Happy Days: A play in Two Acts. New York: Grove Press, 1961.

Oh Les Beaux Jours: Pièce en Deux actes. Paris: Éditions de Minuit, 1963.

. Dias felizes. São Paulo : Cosac Naify, 2010.

CLÉMENT, Bruno. L'Oeuvre sans qualités. Rhétorique de Samuel Beckett. Paris: Seuil, 1994.

HARAWAY, Donna. Manifesto ciborgue. Ciência, tecnologia e feminismo-socialista no final do século XX. Belo Horizonte: Editora Autêntica, 2009.

HARTWIG, Julia. Wiersze amerykanskie. Warszawa: Wydawnictwo Sic, 2002.

JAKOBSON, Roman. Linguística e Comunicação. São Paulo: Cultrix, 1995.

KAFKA, Frank. Contemplação. O foguista. São Paulo: Companhia das Letras, 1999.

KOSELLECK, Reinhart. Futuro passado. Contribuição à semântica dos tempos históricos. Rio de Janeiro: Contraponto, 2006.

MlŁOSZ, Czeslaw. Wiersze wszystkie. Kraków: Znak, 2011.

NUSSBAUM, Martha. Love's Knowledge. Essays on Philosophy and Literature. Oxford: Oxford University Press, 1990.

PAVLENKO, Aneta. Emotions and Multilingualism. Cambrigde: Cambridge University Press, 2005.

POSWIATOWSKA, Halina. Własnie kocham. Indeed I love. Kraków: Wydawnictwo Literackie, 1997.

TSVETÁIEVA, Marina et al. Poetas Russos. Lisboa: Relógio d'Água, 1995. 
WHORF, Benjamin L. Language, Thought, and Reality. London: The MIT Press, 2012.

WIERZBICKA, Anna. Understanding Cultures through Their Key Words. English, Russian, Polish, German, and Japanese. Oxford: Oxford University Press, 1997.

Emotions Across Languages and Cultures: Diversity and Universals. Cambrigde: Cambridge University Press, 1999.

Artigo recebido em junho e aprovado em Agosto de 2013. 